\title{
Aproximación a la creación de las redes de distribución de libros en América a través de las fuentes españolas (segunda mitad del siglo XVI)/
}

\author{
An Approach to the Creation of Books' Distribution \\ Networks in the Americas from the Spanish Sources \\ (Second Half of the Sixteenth Century)
}

Natalia Maillard Álvarez

Universidad Pablo de Olavide, Sevilla

Este artículo analiza las redes comerciales a través de las cuales los libros llegaban y circulaban por América durante el siglo XVI. Para ello se combinan distintos archivos españoles, los cuales nos permiten completar la información ofrecida por los archivos americanos, de forma que podamos tener una idea más precisa sobre el mercado del libro en el ámbito atlántico y quiénes fueron los agentes implicados en el mismo.

Palabras Claves: Comercio de libros; Redes; Libros; Libreros; Siglo XVI.

This article analyses the merchants' networks through which books arrived to the Americas and circulated on it during the Sixteenth century. In order to do so, the documents from different Spanish archives are combined here. Those documents allow us to complete the American sources, having a more precise idea about the book trade in the Atlantic, and who were the agents involved on it.

Keywords: Books trade; Networks; Books; Booksellers; Sixteenth century. 


\section{Introducción}

El Atlántico en la Edad Moderna fue un espacio compartido, en el que personas, bienes e ideas circulaban a través de unas fronteras más porosas de lo que con frecuencia se ha creído. ${ }^{1}$ Esta circunstancia afectó también a los libros, que ya en el siglo XVI eran un producto en buena medida internacionalizado, que se fabricaba a gran escala en algunas ciudades o regiones de Europa, desde donde se distribuía por todo el continente ${ }^{2}$ y también por América, aunque al mismo tiempo funcionasen talleres de imprenta con producciones menores en multitud de lugares, con los que se cubrían sobre todo las necesidades locales. ${ }^{3}$ Por tanto, la organización de la producción y distribución de libros en Europa y América en el Quinientos hace que resulte imposible estudiar ésta en un territorio concreto sin tener en cuenta sus relaciones con los demás.

En el caso español, un elemento clave para explicar la configuración y evolución del comercio de libros a lo largo del siglo XVI es precisamente el horizonte americano, aunque su impacto fuera distinto en los principales núcleos y redes de dicho comercio. Como era de esperar, donde se notó antes y con mayor intensidad tal impacto fue entre los productores y distribuidores de libros de Sevilla, cabecera peninsular de la Carrera de Indias. Diversos aspectos o etapas de esta estrecha relación entre Sevilla y América a través de los libros han sido abordados por varios investigadores; ${ }^{4}$ pero aún queda, tanto en los archivos de esta ciudad como en otros, mucha información por explorar para reconstruir las redes que permitieron la circulación de libros entre Europa y América, y sobre parte de esta documentación se construye el presente artículo. ${ }^{5}$ Los archivos que podrían utilizarse son muchos, y un estudio sistemático de los mismos resulta aquí imposible. Por ello las siguientes páginas se centran sobre todo en dos archivos, que además son precisamente los que ofrecen una información más valiosa y abundante para mis objetivos: el Archivo General de Indias (AGI) y la sección de Protocolos Notariales del Archivo Histórico Provincial de Sevilla (AHPSe),

1 Cañizares-Esguerra, 2009, 237-264.

2 Fevbre-Martin, 2005, 264.

3 Rial Costas, 2013.

4 Entre otros: Griffin, 1992, González Sánchez, 1999, Rueda, 2005 y Gómez Álvarez, 2011.

5 Para reconstruir las redes de circulación de libros entre España y América en los siglos modernos, también deben tenerse en cuenta los archivos de otros países europeos. Semejante tarea excede las posibilidades de este artículo, pero un buen ejemplo de cómo puede contribuir la documentación procedente de otros países al estudio de este tema puede encontrarse en Van Rossem, 2014, 1-50. 
a los que añadiré información encontrada en los trabajos realizados por otros investigadores. El Archivo de Indias es el más conocido y utilizado, aunque todavía quedan campos por explorar, sobre todo para la segunda mitad del siglo XVI. Por su parte, la documentación de los protocolos notariales sevillanos es abundantísima a lo largo de todo el siglo, lo que en cierta forma puede compensar la escasez de documentación del mismo tipo de esa época en América, al menos en el caso de México, donde, en palabras de Nora Jiménez, «la mayor parte de los papeles con los que contamos, son aquellos generados por la actividad inquisitorial». ${ }^{6}$

\section{Primeros pasos del comercio del libro en América}

Los libros viajaron a América de la mano de los primeros descubridores y conquistadores, ${ }^{7}$ pero conforme se extiende el asentamiento de los europeos en América y se consolidan las sociedades y las instituciones indianas es cuando crece la demanda de libros. Para responder a ésta se establecerán impresores en los distintos virreinatos y se crearán redes para la distribución del libro que van desde el librero con tienda abierta en una gran ciudad hasta los vendedores y mercachifles ambulantes que, de lugar en lugar, van vendiendo todo tipo de mercancías. Conocemos los nombres de los primeros impresores en territorio americano, así como de varios libreros. La mayoría de ellos llegaron en la segunda oleada de emigración a Indias, encontrándose con las riquezas del Nuevo Mundo ya repartidas, por lo que, aunque tuviesen más posibilidades de promoción social que los trabajadores sin cualificar, debieron trabajar duro para salir adelante. ${ }^{8}$ Una vez en territorio americano necesitaron seguir en contacto con la metrópolis para proveerse de libros, así como de otras menudencias de imprenta con que abastecían a su público: cartillas, almanaques, imágenes, etc. Tanto la emigración de estos hombres, como su posterior dependencia con respecto a las exportaciones de la Península dejó un rastro en diferentes archivos españoles que es necesario seguir si queremos saber más y comprender mejor cómo funcionó el mercado de libros en la América colonial durante su primer siglo de vida.

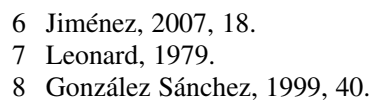


Hasta la década de los cuarenta encontramos todavía pocos libreros en América $^{9}$ y las noticias que a este respecto se encuentran en las fuentes españolas están en su mayoría vinculadas a los Cromberger, familia de impresores de origen alemán instalados en Sevilla, que detentaron el monopolio de exportación de libros y cartillas a la Nueva España, ${ }^{10}$ donde además Juan Cromberger (el segundo miembro de la dinastía) envió a uno de sus empleados con la primera imprenta que se instaló en el continente. ${ }^{11}$

Conforme más documentación sale a la luz, más patente queda que también hubo libreros fuera del virreinato novohispano desde fechas tempranas. En 1526 una real cédula dirigida a las autoridades de Santo Domingo, en La Española, pedía a éstas que comprobaran si Diego de Pedrosa, vecino de Sevilla, había sido factor de Andrea de León de Dey, mercader de libros vecino de Salamanca, y si durante más de 15 años no había querido rendir cuentas a su patrón. ${ }^{12}$ En 1548 era don Juan de Valle, primer obispo de Popayán (en la actual Colombia), quien solicitaba viajar a su diócesis con un librero de quien no da el nombre, el cual llevaba dos balas de libros. Finalmente se le concedió la merced que pedía, aunque con dos condiciones: «que no pase nyngunos libros de los que por nos están proybidos que no se pasen a aquellas partes», y que el librero no estuviera casado. ${ }^{13}$

A pesar de que puedan encontrarse ejemplos como estos, durante la primera mitad del siglo el dominio de la imprenta sevillana en el mercado americano fue innegable. Juan Cromberger era, según Griffin, «el impresor español que imprimía ediciones especialmente para aquel mercado, incluso

9 Rojo Vega, 1992, 125.

10 Griffin, 1992, 165.

11 Juan Cromberger fue también responsable de la llegada a Nueva España de Guido de Lavezaris con un cargamento de libros en los años 30.Wagner, 1994.

12 AGI, Indiferente, 421, L.11, 88-89. Este Andrea debe ser el mismo a quien se encomendó la impresión de las obras del Tostado en Venecia, aunque su muerte interrumpió el proceso. Parece que Andrea fue padre de Lorenzo de Liondedey, librero e impresor establecido también en Salamanca, originario de una familia patricia de Pésaro (el apellido original fue Ondedey, escrito a veces Hondedey). Del matrimonio de Lorenzo con Mari Rodríguez Nieta nació en 1534 Andrea de Liondedei, quien también ejerció como librero. El hijo de este último y de Inés de Paz, llamado Antonio de Paz, recibió en 1556 una licencia para ir a México a reunirse con su madre, quien ya residía en la capital novohispana casada en segundas nupcias con el oidor Pedro de Morones. AGI, Indiferente, 2048, N.54 y AGI, Pasajeros, L.3, E. 3337. Entre los testigos que presentó se encuentra Andrea de Portonariis, quien declara había conocido al padre de Antonio en Italia. Antonio volvió a España, dado que en 1570 está en Salamanca y se le llama impresor, aunque parece que no ostentó la titularidad de ningún taller. Mano González, 1998, 108 y Delgado, 1996, I, 387-388.

13 AGI, Indiferente, 1964, L.10. En todas las transcripciones de documentos que se recogen en este artículo he respetado la ortografía original, añadiendo únicamente acentuación y puntuación para facilitar su lectura. 
en lenguas amerindias»..$^{14}$ En 1542 , la viuda y herederos de Juan Cromberger renovaron el monopolio de exportación por otros diez años. Sin embargo, en esta ocasión, buena parte de los libreros e impresores sevillanos se revelaron, comprometiéndose a enviar libros «a preçios moderados» y a llevar también imprentas «y que en ellas se ynpriman». ${ }^{15}$ Que ofreciesen al rey aceptar una ganancia del $25 \%$ del precio de los libros colocados en América si anulaba el monopolio es un buen indicio de lo rentable que resultaba el negocio. Al otro lado del Atlántico, en 1545 los potenciales clientes de los libreros también se quejaban de la mala administración del monopolio que venían haciendo los Cromberger tras la muerte de Juan:

Sus herederos no han proveido ni proveen los libros necesarios, de que se recibe daño y hay falta, y por la merced nadie los trae: suplicamos a vuestra majestad mande a los oficiales de la Casa de la Contratación de Sevilla hagan las diligencias necesarias con los dichos herederos para que cumplan lo asentado o se les revoque la merced para que todos tengan facultad de los traer. ${ }^{16}$

\section{Cambio y consolidación de las redes de comercio en la segunda mitad del Quinientos}

En la configuración de las redes de comercio de libros en América durante el Quinientos, los años cincuenta se revelan como el momento crítico y, en mi opinión, Sevilla y sus libreros tienen un papel fundamental en el mismo. Para entonces el monopolio de los Cromberger había caducado, lo que permitió al resto de los profesionales del libro impreso en Sevilla acceder plenamente al ansiado mercado americano. Si bien las «puertas» del comercio de libros con América estaban abiertas a cualquiera dispuesto a invertir capital sin necesidad siquiera de ser librero o impresor. Así lo entendió Cebrián de Caritate, un mercader muy vinculado a América, pero también al mundo de la librería sevillana, ${ }^{17}$ quien en 1550 entregó libros

14 Griffin, 1991, 119.

15 Gestoso, 1924, 103-104.

16 Jiménez, 2007, 24.

17 En 1530 Cebrián de Caritate se declaraba aragonés y estante (es decir, aún no era vecino) en Sevilla; entonces dio un poder para cobrar deudas en Venezuela y Cuba. AHPSe, 11514, 1198. En 1548 intentó ya pasar un libro por el istmo de Panamá, por el que los oficiales reales le exigieron el pago de la alcabala, aunque finalmente la Corona le dio la razón al mercader. Lohmann Villena, 2000, 5. En Sevilla, Caritate fue padrino de Pedro de Sansorel, hijo del librero homónimo de quien tendremos oportunidad y necesidad de hablar en este artículo. Archivo de la Parroquia del Sagrario (APS), Libro 3..$^{\circ}$ de Bautismos, 14. 
(sin especificar el título) «y otras cosas» por valor de 1.000 maravedíes a un tal Josepe de Amberes, librero, hijo de Juan de Amberes. ${ }^{18}$ Las mercancías irían cargadas en el navío San Cosme y San Damián que se preparaba en esos momentos en el puerto de Sevilla para emprender su marcha a Nombre de Dios. En esta pareja Caritate es el socio capitalista y Josepe de Amberes pone su oficio al servicio de la empresa común. Una vez descargados los libros en Tierra Firme, Josepe se comprometía a llevarlos a la ciudad de Panamá y de allí pasar al Perú, donde residiría en Lima o «en la çiudad donde estuviere e residere el Abdençia y Chançillería Real de su magestad» durante seis años. ${ }^{19}$

En la década de los cincuenta se encuentran todavía pocas evidencias sobre el envío de libros a América. La reciente apertura del mercado, junto a la crisis que se produjo en la industria del libro sevillano, ${ }^{20}$ puede explicar este fenómeno. De hecho, el librero que a través de los protocolos notariales se nos presenta como más activo en la Carrera de Indias en esos primeros años no es sevillano, sino medinense, Alejo de Herrera, quien envió libros tanto al virreinato de Nueva España como al Perú. Puede ser que cuando finalmente se extinguió el predominio de los Cromberger en la producción y comercialización de libros con destino a América, los sevillanos no obtuvieran los resultados esperados, en primer lugar porque durante la segunda mitad del Quinientos la ciudad deja de ser la principal productora de libros con destino hacia América para convertirse más bien en un puente por el que los libros impresos en otros lugares de España y Europa pasaban al Nuevo Mundo, aunque las ediciones sevillanas no dejaron tampoco de cruzar el Atlántico. ${ }^{21}$ El protagonismo de la exportación de libros al Nuevo Mundo va a pasar de los impresores a los libreros y mercaderes de libros, en un movimiento paralelo al que se produce en la propia ciudad y que traduce, no sólo la crisis y decadencia de su imprenta, sino también la progresiva captación del mercado por parte de algunas grandes casas del libro europeas que, funcionando como auténticas multinacionales del libro, van a llegar al mercado americano a través de Sevilla.

18 De Juan de Amberes se dice era natural de «Herrontales», posiblemente la localidad flamenca de Herentals, en la provincia de Amberes.

19 AHPSe, 5887, 1226-1228.

20 Griffin, 1992, 157-164.

21 En 1559 el gobernador indígena de Michoacán, Antonio Huitziméngari, adquirió una serie de libros entre los que se encontraban al menos dos ediciones sevillanas, In sacrosanta Iesu Christi quator evangelia, impreso por Pedro de Luján en 1554, y el Libro de música para vihuela, de Miguel de Fuenllana, salido del taller de Martín de Montesdoca el mismo año. Jiménez, 2002. 
La documentación notarial sevillana me ha permitido localizar a más de una veintena de profesionales del libro implicados en la Carrera de Indias en la segunda mitad del siglo XVI (aunque no sólo traficasen con libros, como veremos). De ellos sólo dos, Juan Varela de Salamanca y Juan Gutiérrez, son fundamentalmente impresores, el resto son libreros o mercaderes de libros. De hecho, hay que aclarar que los testimonios de envíos de libros a América por parte de Juan Gutiérrez se concentran fundamentalmente en los años en que fue librero, mientras que Juan Varela de Salamanca tuvo en América intereses distintos al libro, al menos en función de la documentación conocida. ${ }^{22}$

Varios factores van a favorecer el aumento de envíos de libros a América en torno a 1560, como la organización del sistema de flotas y el establecimiento en la ciudad de algunos grandes mercaderes de libros en contacto con las principales casas de Castilla y Europa, como Andrea Pescioni o Pedro de Portonariis. A partir de 1558 se encuentran en los protocolos notariales noticias sobre los contactos de los libreros sevillanos con Indias casi cada año, a veces se trata de envíos de libros u otras mercancías, y otras de reclamaciones de deudas a particulares o a la Casa de la Contratación, donde los pleitos debieron ser frecuentes.

Aunque la documentación notarial no sea una fuente completa para el estudio del libro en la Carrera de Indias, sí nos permite tener una idea bastante exacta de quienes eran sus protagonistas en Sevilla, comprobando como los libreros implicados en la misma vienen a coincidir casi al completo con quienes ocupan la cabecera de su profesión en la ciudad. En las décadas de los sesenta y setenta, por ejemplo, los mercaderes de libros Francisco de Aguilar y Andrea Pescioni (quien posteriormente también fue impresor) son los que mantienen contactos más frecuentes con América. Ambos fueron incluso dueños de navíos que participaron en la Carrera de Indias. ${ }^{23}$ Aguilar llegó a fundar una compañía en 1573 con Juan Núñez de

22 Todavía el mismo año de su muerte (1555) envió Juan Varela de Salamanca a Diego Díaz, vecino y natural de Sevilla, como factor a Nueva España, aunque no tengo noticias que lo vinculen con el comercio de libros. AGI, Pasajeros, L. 3, exp. 3195.

23 Aguilar poseyó media nao llamada San Juan, que fue de capitana de la flota a la ciudad de Nombre de Dios, AHPSe, 3468, s.f., mientras que Pescioni era propietario de una nave llamada San Lázaro, que en agosto de 1580 se preparaba para partir con la flota del Caribe. AHPSe, 10757, 709710; AHPSe, 10758, 542-543; AHPSe, 10761, 830-831. Gracias a los documentos del Archivo General de la Nación de México (AGN), transcritos y publicados por Francisco Fernández del Castillo, sabemos algo más de los contactos y envíos de Pescioni a Nueva España, donde debía ser muy conocido entre los libreros, a juzgar por la forma en que Benito Boyer y otros libreros de España hablan de él en 
Tapia, mercader de Tocaima (en la actual Colombia), con un capital inicial de 13.500 ducados. La compañía, fundada por seis años, tenía como objetivo la exportación de mercancías en general a Cartagena de Indias, donde Núñez de Tapia tendría tienda abierta. Sin embargo, la prematura muerte de Francisco de Aguilar frustró su proyecto. ${ }^{24}$

Andrea Pescioni no sólo participó en la Carrera de Indias por su cuenta, sino que también sirvió de intermediario a otros, ${ }^{25}$ aunque finalmente parece que abandonó el mundo del libro después de una etapa como tipógrafo. A partir de los ochenta y noventa el protagonismo, al menos por las huellas que han dejado en el AHPSe, pasará a Diego Mexía y a su hijo Fernando ${ }^{26}$ y a Jácome López, aunque no son los únicos implicados en este negocio.

En el siguiente cuadro están incluidas las noticias sobre envíos de libros hechos por libreros o por otras personas a América entre 1550 y 1600 que he encontrado en los protocolos notariales sevillanos y en las cartas que los libreros españoles enviaron a México. ${ }^{27} \mathrm{El}$ objetivo es meramente indicativo, nunca estadístico, pero creo que reviste el suficiente interés como para ofrecerlo.

las cartas que enviaban a Indias (Benito Boyer: «y el Señor Andrea Pesconi ni nadie de Sevilla en mi conciencia, no puso los dichos [precios] y no tiene vuestra merced que culparle»; Mexía: «envió poder [Benito Boyer] a Andrea Pisioni, y hablóme el Andrea y contelé lo que pasaba, y otro día fuimos yo y Andrea a la Contratación y había parecido el un registro y hallamos la una partida»). Este autor recoge también dos envíos realizados por Pescioni a México: dos cajas en 1578 y seis en 1581, cuando ya había iniciado su aventura como impresor. Fernández del Castillo, 1982, 283, 285, 306, 378 у 389.

24 Aguilar traspasó su parte de la compañía al mercader sevillano Miguel de Medrano, padre del poeta Francisco de Medrano. AHPSe, 3467, 999 y 1000-1002. En su testamento, redactado en plena mar en 1582, Juan Núñez de Tapia declara que la compañía aún existe, aunque parece que se dedica a todo tipo de productos, incluidos esclavos. Sin embargo, también confiesa «que debo a Francisco Rodríguez, librero [precisamente quien compró la tienda de Francisco de Aguilar (González y Maillard, 2003, 53)], que bibe en cal de Génova, en Sevilla, ochenta o noventa reales de resto de libros que por olvido se los dexé de pagar». AGI, Contratación, 222, N.2, R.1. Ese mismo año Francisco Rodríguez envió a su hermano Diego como representante al Perú y Santa Fe para que cobrara unas deudas (de Francisco de Valenzuela y Pedro de Cárdenas); declara tener como apoderado a Juan Núñez de Tapia, aunque lo sitúa como mercader limeño. AHPSe, 3502, 140-141.

25 Encontraremos a Pescioni recibiendo en la Casa de la Contratación el dinero que había llegado para otros, como el sevillano Juan Bautista de Alfaro en 1567, AHPSe, 3433, 68; el medinense Mateo del Canto, quien le traspasó a Pescioni el poder que él mismo tenía de Vicente de Miles para recoger el dinero que les había llegado a la Casa de la Contratación en 1568, AHPSe, 3435, 700; o los también sevillanos Alonso Montero y Ana de los Reyes en 1580, AHPSe, 14290, 328.

26 Rueda Ramírez, 1998.

27 Sánchez y Testón, 1999. Pueden encontrarse más noticias sobre envíos de libros (u otras mercancías) a Indias realizados por libreros en el siglo XVI procedentes del AHPSe en González y Maillard, 2003; Álvarez Márquez 2007, 230-241 y en Álvarez Márquez, 2009. 


\section{APROXIMACIÓN A LA CREACIÓN DE LAS REDES DE DISTRIBUCIÓN DE LIBROS}

\begin{tabular}{|c|c|c|c|c|}
\hline Vendedor / Cargador & Intermediario / Comprador & Mercancía & Destino & $A \tilde{n} o^{28}$ \\
\hline Francisco Suárez, sastre & Hernando Díaz, mercader & $\begin{array}{l}\text { Mercancía variada y dos } \\
\text { libros }\end{array}$ & Indias & 1550 \\
\hline Cebrián de Caritate & Josepe de Amberes, librero & Libros y otras cosas & Tierra Firme & 1550 \\
\hline $\begin{array}{l}\text { Diego de la Torre y Pedro } \\
\text { Alonso, tundidor }\end{array}$ & Convento de Coyoacán & Libros & Nueva España & 1550 \\
\hline $\begin{array}{l}\text { Gaspar de Luján, } \\
\text { bordador }^{29}\end{array}$ & Alonso Rodríguez Catalán & $\begin{array}{l}1 \text { caja grande de libros, vino } \\
\text { y otras cosas }\end{array}$ & Nueva España & 1551 \\
\hline Alejo de Herrera, librero & Juan Hernández & 4 cajas de libros & Nueva España & 1555 \\
\hline $\begin{array}{l}\text { Gabriel de Almazán, } \\
\text { librero }\end{array}$ & $\begin{array}{l}\text { Juan de Guevara, escribano } \\
\text { de nao }\end{array}$ & $\begin{array}{l}\text { Libros de todas suertes, } \\
\text { encuadernados }\end{array}$ & Nueva España & 1556 \\
\hline Alejo de Herrera, librero & $\begin{array}{l}\text { Juan Farfán de Illescas, } \\
\text { mercader }\end{array}$ & 1 caja de libros & Tierra Firme & 1558 \\
\hline $\begin{array}{l}\text { Andrea de Portonariis, } \\
\text { librero }\end{array}$ & Fray Juan de San Román & Ciertos libros & Nueva España & 1561 \\
\hline $\begin{array}{l}\text { Pedro de Portonariis, } \\
\text { librero }\end{array}$ & Diego de San Román & $\begin{array}{l}2 \text { cajas y } 1 \text { cofre de } \\
\text { mercaderías }\end{array}$ & Nueva España & 1562 \\
\hline Alonso Montero, librero & $\begin{array}{l}\text { Francisco Morales } \\
\text { Camacho, maestre de nao }\end{array}$ & 1 caja de libros & Puerto Rico & 1562 \\
\hline Alonso Montero, librero & Juan de Ribera & 1 caja de libros & Puerto Rico & 1562 \\
\hline $\begin{array}{l}\text { Miguel Jerónimo y Juan } \\
\text { Gutiérrez, libreros }\end{array}$ & $\begin{array}{l}\text { Baltasar García y Diego } \\
\text { de Agúndez }\end{array}$ & 2 cajas de libros & Nueva España & 1563 \\
\hline $\begin{array}{l}\text { Francisco de Aguilar, } \\
\text { librero }\end{array}$ & $\begin{array}{l}\text { Juan de Rebollar, escribano } \\
\text { de nao, y Diego Gamboa }\end{array}$ & 2 cajas de libros & Nueva España & 1564 \\
\hline $\begin{array}{l}\text { Pedro de Portonariis, } \\
\text { librero }\end{array}$ & $\begin{array}{l}\text { Bartolomé de Torres o } \\
\text { Domingo de Portonariis }\end{array}$ & 1 cargazón de libros & Nueva España & 1565 \\
\hline $\begin{array}{l}\text { Juan Gutiérrez, librero e } \\
\text { impresor }\end{array}$ & Diego de Sansorel & 1 caja de libros & Nueva España & 1566 \\
\hline $\begin{array}{l}\text { Francisco de Aguilar, } \\
\text { librero }\end{array}$ & Francisco Núñez & 1 caja de libros & Tierra Firme & 1567 \\
\hline $\begin{array}{l}\text { Juan Bautista de Alfaro, } \\
\text { librero }\end{array}$ & Diego de San Martín & 3 cajas de libros & Nueva España & $(1567)$ \\
\hline
\end{tabular}

28 Los documentos utilizados para la elaboración de este cuadro no siempre se realizaron en la misma fecha que el envío, puesto que en ocasiones la noticia procede de la reclamación de deudas hecha años después. Por desgracia no siempre se aclara cuando se mandaron los libros a América. Los años entre paréntesis corresponden a la fecha de aquellos documentos que no nos proporcionan dicha información.

29 Gaspar de Luján era cuñado del impresor Doménico de Robertis y padre del también impresor Pedro de Luján. Los libros que envió a América, cuyo cobro su hijo reclamaba todavía en 1563 , bien pudieron salir del taller de uno de ellos. 
NATALIA MAILLARD ÁLVAREZ

\begin{tabular}{|c|c|c|c|c|}
\hline Vendedor / Cargador & Intermediario / Comprador & Mercancía & Destino & Año \\
\hline $\begin{array}{l}\text { Francisco de Mansilla y } \\
\text { Francisco Díaz, librero }\end{array}$ & Gabriel de Mansilla & 116 Flor Sanctorum & Los Ángeles & 1568 \\
\hline $\begin{array}{l}\text { Francisco de Aguilar, } \\
\text { librero }\end{array}$ & $\begin{array}{l}\text { Juan de Castillo, obispo } \\
\text { de Cuba }\end{array}$ & 84 libros & Cuba & 1569 \\
\hline $\begin{array}{l}\text { Francisco de Aguilar, } \\
\text { librero }\end{array}$ & Fray Juan Méndez & 2 cajas de libros & Tierra Firme & 1569 \\
\hline $\begin{array}{l}\text { Francisco de Aguilar, } \\
\text { librero }\end{array}$ & Juan de Cuenca & 1 partida de libros & Tierra Firme & 1570 \\
\hline $\begin{array}{l}\text { Francisco de Aguilar, } \\
\text { librero }\end{array}$ & $\begin{array}{l}\text { Alonso Vázquez de } \\
\text { Moncayo, mercader }\end{array}$ & 2 partidas de libros & Tierra Firme & 1570 \\
\hline Pedro y Juan de la $\mathrm{Hoz}^{30}$ & & $\begin{array}{l}\text { «Doze libros de romançe } \\
\text { para leer de diferentes } \\
\text { ystorias» }\end{array}$ & Perú & 1570 \\
\hline $\begin{array}{l}\text { Ldo. Gómez de León, } \\
\text { autor }\end{array}$ & Gómez de León & Varios libros $^{31}$ & -- & 1570 \\
\hline $\begin{array}{l}\text { Francisco de Aguilar, } \\
\text { librero }\end{array}$ & Diego de San Martín & 5 cajas de libros & Nueva España & 1571 \\
\hline $\begin{array}{l}\text { Alonso de Fuenmayor, } \\
\text { librero }\end{array}$ & Diego de San Martín & 1 caja de libros & Nueva España & $(1571)$ \\
\hline Juan de Herrera & Diego de San Martín & 2 cajas de libros & Nueva España & 1574 \\
\hline Andrea Pescioni, librero & Martín de Porras & $\begin{array}{l}\text { 2'5 cofres de libros } \\
\text { encuadernados }\end{array}$ & Nueva España & 1574 \\
\hline $\begin{array}{l}\text { Francisco de Aguilar, } \\
\text { librero }\end{array}$ & Fray Diego Gutiérrez & 3 cajas de libros & Perú & 1574 \\
\hline $\begin{array}{l}\text { Juan Gutiérrez, librero e } \\
\text { impresor }\end{array}$ & Diego de Sansorel & 1 caja de libros & Nueva España & $(1575)$ \\
\hline $\begin{array}{l}\text { Faustino de Magarino, } \\
\text { librero }\end{array}$ & Hernán Sánchez Munon & 2 cajas de libros & Nueva España & $(1580)$ \\
\hline
\end{tabular}

30 Leonard Irving ofrece información sobre un tal Francisco de la Hoz, asentado en el virreinato de Perú, quien, de partida hacia España en 1583, se comprometió a volver con un cargamento de libros para un mercader. Leonard, 1979, 211.

31 Quien marcha a Indias es el sobrino del autor, motivo por el cual ordenó un testamento en el que declaraba llevar en una caja, con otras mercancías, varios ejemplares sin encuadernar de una obra de su tío, estipulando que el resultado de la venta se le enviase a éste pues los ejemplares eran suyos. La obra era la Ynformacionum decisionum et responsorum iuris Centuria, impresa en Sevilla por Pedro Martínez de Bañares en 1564. Escudero y Perosso, 1999, 616.

32 En 1573, Alonso Magarino, hijo de Faustino Magarino y Catalina de Toro solicitaba licencia para pasar a Nueva España como paje del doctor don Sancho Sánchez de Muñón, maestrescuela de la Catedral de México. Declara que tanto sus padres como sus abuelos eran naturales de Sevilla y cristianos viejos, y entre sus testigos se encuentran los libreros Hernán Rodríguez y Juan Hidalgo. Los dos son libreros modestos, aunque del segundo sabemos que en 1590 recibió cien pesos que le enviaba desde la ciudad de México Rodrigo Hidalgo, vecino de la misma. AHPSe, 14368, 618v. 
APROXIMACIÓN A LA CREACIÓN DE LAS REDES DE DISTRIBUCIÓN DE LIBROS

\begin{tabular}{|c|c|c|c|c|}
\hline Vendedor / Cargador & Intermediario / Comprador & Mercancía & Destino & Año \\
\hline Ana de los Reyes & Gregorio de Mansilla & Ciertos libros & Nueva España & $(1580)$ \\
\hline $\begin{array}{l}\text { Vicente de Portonariis, } \\
\text { librero }\end{array}$ & Juan de Treviño & 4 cajas de libros & Nueva España & 1583 \\
\hline Benito Boyer, librero & Diego Navarro & 40 cajas de libros & Nueva España & 1584 \\
\hline Jácome López, librero & $\begin{array}{l}\text { Luis de San Millán, } \\
\text { mercader }\end{array}$ & 31 obras & Perú & 1585 \\
\hline $\begin{array}{l}\text { Isabel Cornejo } \\
\text { Viuda de V. Portonariis }\end{array}$ & Juan de Treviño & 7 cajas de libros & Nueva España & 1585 \\
\hline Diego Mexía, librero & Juan de Treviño & Libros y sedas & Nueva España & 1585 \\
\hline Diego Mexía, librero & Baltasar de Cabrejas & 8 cajas de libros & Nueva España & 1585 \\
\hline Antonio Vivas, librero & Juan de Treviño & 10 cajas de libros & Nueva España & 1585 \\
\hline Jácome López, librero & Baltasar de Navarrete & 8 cajas de libros & Perú & 1586 \\
\hline Juan Muñoz, librero & $\begin{array}{l}\text { Pedro de Castro Casaus } \\
\text { y Juan de Zaldívar }\end{array}$ & 4 cajas de libros & Perú & 1586 \\
\hline Diego Rodríguez, librero & $\begin{array}{l}\text { Alonso del Canto, mercader } \\
\text { de libros }\end{array}$ & Libros & Perú & 1589 \\
\hline Lucas de Iturbe & Juan Arce Machain & Mercancías y 14 libros & Nueva España & 1590 \\
\hline Diego Mexía, librero & Francisco de Velasco & 5 cajas de libros & Nueva España & 1591 \\
\hline Jácome López, librero & Cristóbal Vergel & 11 cajas de libros & Tierra Firme & 1592 \\
\hline Diego Mexía, librero & Íñigo de Iribe, mercader & 15 cajas de libros & Tierra Firme & 1594 \\
\hline Sebastián de Cetina & Alonso de Lerma & 1 cajón de libros & Nueva España & 1600 \\
\hline Diego Mexía, librero & Ldo. Juan de Sestara & «Unas obras de rebuxo» & Perú & $(1600)$ \\
\hline $\begin{array}{l}\text { Alonso Cubilo, escribano } \\
\text { público }\end{array}$ & Pedro de Campos Guerrero & «300 Viaje de Jerusalem» & Nueva España & $(1600)$ \\
\hline
\end{tabular}

Al margen de libros, tanto impresores como libreros tuvieron otros intereses y negocios en América, y en ocasiones fueron incluso más lucrativos que los propios impresos..$^{33} \mathrm{~A}$ pesar de ello no hemos encontrado testimonios de la implicación de los libreros en el tráfico de papel y objetos de escritura con destino a América. Estos productos estaban en manos de mercaderes más generalistas, que a veces también negociaban con libros. Los envíos de libros a América respondían a distintas causas: bien podía ser que

33 Griffin, 1992, 93 y 130-132. Como ejemplo podemos poner también a Andrea Pescioni, quien en 1595 envió doce pipas de vino a Nueva España. AHPSe, 3550, s.f. 
el mercader de libros sevillano enviara un cargamento de libros con (o a algún) agente como los que hemos visto tenían instalados en América; pero también es posible que los libreros del Nuevo Mundo les hiciesen peticiones concretas. Con ese objeto Pedro Treviño, hermano del librero mexicano Juan de Treviño se presentó en Sevilla con 7.000 reales y un memorial de libros en $1580 .{ }^{34}$ De ambos hermanos volveré a hablar en este artículo.

En palabras de Anastasio Rojo, «nuestro gran problema, a la hora de buscar relaciones entre los grandes libreros españoles del siglo XVI, que son medinenses, y América, es definir qué pinta Sevilla en ellas»; como Sevilla era escala obligada en el viaje de los libros hacia América, esos grandes libreros necesitaban agentes o socios en la ciudad, aunque también es posible «que la exportación de libros a América fuese hecha fundamentalmente por los sevillanos, limitándose los grandes libreros a unas escasas y grandes operaciones $\gg .{ }^{35}$

Por mi parte, puedo decir que no he encontrado ninguna compañía firmada entre los libreros medinenses y los sevillanos para la exportación de libros a América, aunque las relaciones entre los dos colectivos fueron muy estrechas a lo largo de este periodo, quedando claro que las ferias de Medina eran uno de los grandes centros de aprovisionamiento de los sevillanos. Aunque esas relaciones no fueron siempre amigables, y quizás a algunos sevillanos no les hizo gracia que los «extranjeros» medinenses se hicieran con las ganancias del mercado americano. ${ }^{36}$

\section{Los primeros libreros en América}

Los archivos españoles nos pueden dar también información sobre quiénes eran y cómo se organizaban los libreros en Indias, con la que completar la que proporcionan las fuentes americanas. Por ejemplo, la documentación notarial sevillana lleva a intuir la creación de una red de libreros propia en el continente americano, que elige como núcleos de redistribución de las mercancías llegadas de Europa las capitales de los virreinatos o aquellas ciudades donde las instituciones coloniales garantizasen un

34 AHPSe, 11592, 763.

35 Rojo Vega, 1992, 121.

36 En 1586 el librero sevillano Antonio Vivas escribió a Juan de Treviño informándole de que Juan Boyer había cargado las famosas biblias de Vatablo secretamente, y advirtiéndole «mire vuestra merced no le engañen estos extranjeros». Sánchez Rubio y Testón Rodríguez, 1999, 171-174. 
público necesitado de libros por razones profesionales. Los primeros libreros del continente eran todavía hombres de dos mundos: nacidos en Europa (generalmente en España) y establecidos en América, donde encontrarían una clientela más escasa y dispersa que en España, pero también más necesitada e incluso ávida de libros, dada la mayor dificultad para encontrarlos. ${ }^{37}$ Pocos de esos hombres vuelven definitivamente a España, aunque también encontramos a más de uno que atraviesa varias veces el Atlántico, como Juan Fajardo. ${ }^{38}$ Un caso particular es el de Antonio Vivas: existe una cédula de mayo de 1576 otorgando licencia a este librero para pasar a Nueva España, obligándose a ejercer su oficio; sin embargo, sólo dos años después encontramos a un Antonio Vivas establecido en Sevilla, donde creó una amplia red de contactos tanto en España como en otros puntos de Europa (Lyon y posiblemente Amberes), además de seguir implicado en la Carrera de Indias (véase, por ejemplo, la nota 37).

El primer paso para iniciar la aventura americana legalmente era pasar por Sevilla y obtener la licencia de las autoridades, que al menos en teoría prohibían el paso de extranjeros, así como de conversos, herejes y sus descendientes. Esto motivó la estancia más o menos prolongada en la ciudad de los hombres que después encontraremos ejerciendo como impresores o libreros al otro lado del Atlántico, pero también de otros que pasaron a América con esta intención (y que quizás llegaron a ejercer también) pero de los que no tenemos más noticias, por ahora. Algún caso encontramos también en el que la participación en la Carrera de Indias es anterior a la marcha a América, como ocurrió por ejemplo con Pedro Balli, quien fuera tanto librero como impresor en el Nuevo Mundo: ${ }^{39}$ al menos en 1567

37 El 10 de marzo de 1578 llegaba una carta a la Inquisición mexicana de su comisario en Nicaragua, quien declaraba «Los libros prohibidos contenidos en la carta que vuestras señorías me hizieron merced de enviar no los ay en esta prouincia, que así como es pobre y mísera lo es también de libros». AGN, Inquisición, vol. 90, exp. 41, antes 7.

38 Juan Fajardo llegó a Nueva España en 1570 y desde entonces tenía tienda de libros en México. En 1573, a la edad de 26 años y siendo aún soltero, regresó a España para ocuparse de sus negocios y comprar libros (AGI, Indiferente, 2055, N.55), pero también para llevarse consigo a su hermano, de 14 años (AGI, Indiferente, 2054, N. 109). Consiguió la licencia y regresó a México en 1574 (AGI, Pasajeros, L.5, E. 3565); siguió haciendo viajes con bastante frecuencia, y en una de sus visitas a España debió de contraer matrimonio, porque en 1576 pedía licencia para volver a Castilla, donde se encontraba su esposa, con la intención de regresar a México con ella (AGI, Indiferente, 2058, N.14). En 1573 Andrea Pescioni apoderó a un tal Juan Fajardo (aunque le nombra vecino de Sevilla), para que cobrara todas sus deudas en México y Nueva España, además de asegurar que Alonso de Fuenmayor, vecino de México, le devolvería el dinero adelantado por el flete de su mujer y su cuñada a Nueva España (AHPSe, 3458, 869-870).

39 Fernández del Castillo, 1982, 554. 
apoderó a Pedro de Portonariis, entonces residente en Sevilla, para cargar libros a su nombre con destino a América, mientras que dos años después era Portonariis quien le apoderaba a él para cobrar sus deudas en México con Bartolomé de Torres, aprovechando que había obtenido licencia para viajar allí. ${ }^{40}$

Muchos de los libreros que partían de Sevilla con objeto de instalarse en América van a ir como agentes de otros mercaderes de libros (o de mercaderes sin más, como hemos visto en el caso de Cebrián de Caritate), que pueden hacerse cargo de su viaje a Indias y de suministrarles mercancías, aunque una vez allí pudieran también trabajar de manera independiente, siguiendo un esquema de comportamiento común a los agentes de los grandes libreros en Europa. Esta circunstancia une, por ejemplo, la biografía de tres hombres que en todos los casos viajaron a América como factores de otros mercaderes de libros más importantes que permanecían en Sevilla: el librero Juan Fernández, de quien desconozco si trabajaba en Sevilla, pagó en 1555 veinte ducados por su pasaje a Indias, donde se dirigía con cuatro cajas de libros propiedad del mercader de libros Alejo de Herrera; ${ }^{41}$ el gallego Juan de Treviño, se instaló y trabajó en Sevilla durante varios años, adiestrándose en el oficio, antes de decidirse a probar fortuna en Indias, donde llegó como factor del mercader de libros Francisco de Aguilar; ${ }^{42}$ mientras que Gabriel Montero de Espinosa marchó a México como factor de su padre Alonso Montero, aunque poco después volvió a la Península.

En otras ocasiones encontramos que los libreros no viajan como factores de otros, sino que han sido «llamados» desde América, en general por parientes. Es el caso de Gaspar de la Fuente, librero de Alcalá de Henares, quien dice haber sido reclamado por sus deudos de Tierra Firme y Lima, aunque después aclara que quien le llamó fue su primo Pedro de Caballos, hombre rico instalado en México. ${ }^{43}$ Similar es el caso de Pedro Treviño: su

40 AHPSe, 3434, 858-859; AHPSe, 3441, 922; AGI, Pasajeros, L.5, E. 2278.

41 AHPSe, 3389, 429; AHPSe, 3397, 276v-277r. En 1557 Alejo de Herrera aún estaba esperando el dinero procedente de estos libros. AHPSe, 3397, 276v-277r.

42 AHPSe, 3468, s.f. Un caso similar puede ser el de Juan Martín Durán: en 1550 estaba avecindado en Sevilla y compró libros del impresor Pedro de Luján (AHPSe, 10578, 761), mientras en la década de 1570 encontramos a un librero de igual nombre instalado en Lima. Guibovich, 2003, 118.

43 AGI, Indiferente, 2078, N. 123. Gaspar quería pasar a Indias con su esposa y sus dos hijos muy pequeños. En el documento, fechado entre 1591-1604, se le describe como «de buena estatura, rubio, flaco, pecoso en la cara, de hedad de treinta años», y su mujer «pequeña, flaca, morenita de rostro, de hedad de beinte y dos años». Como testigos presenta a un tal López, mercader de libros en Alcalá de Henares, Francisco del Val, librero de Madrid, y Pedro del Carpio, residente en Sevilla. 
hermano, Juan de Treviño, llegó a Indias como queda dicho, en calidad de factor de Francisco de Aguilar, y una vez instalado allí llamó a Pedro para que le ayudara en el negocio. Este pide licencia para ir a Nueva España en 1573, declarando que ya es librero y vecino de Sevilla, aunque en mis investigaciones sobre el comercio de libros en dicha ciudad nunca encontré rastro sobre él, quizás porque trabajaba en la tienda de otro, igual que hiciera su hermano. De nuevo se dice que ha sido «llamado» y aparecen las cartas como el vínculo necesario para mantener familias y negocios. En este caso, Pedro es aún soltero y su hermano le ha enviado dinero para costear el viaje. ${ }^{44}$

En el AGI se conserva también el expediente y la licencia para pasar a Indias de Catalina Agudo (o Aguda) en $1576 .{ }^{45}$ En este documento se dice casada en segundas nupcias con Antonio Ricardo, librero instalado entonces en México y que terminaría siendo a los pocos años el primer impresor del Perú. Se aclara que Catalina (que obtiene permiso para hacer el viaje

44 AGI, Indiferente, 2054, N.32. Como testigos aparecen al menos dos libreros: Cebrián Gómez y Francisco Díaz, quien declara haber tenido a Pedro en su casa porque no tenía forma de mantenerse. Finalmente la licencia se le concede, aunque con condición de que use su oficio. En 1585 un mercader sevillano llamado Juan Mejía escribía a Juan Treviño: «De su hermano de vuestra merced no se sabe; ha 15 meses que escribió a su compadre, deudo de Cebrián Gómez, que estaba bueno y rico». Sánchez Rubio y Testón Núñez, 1999, 171-174. En un listado de libros redactado en Manila en 1583 puede leerse «memoria de los libros sigtes q traygo yo trebiña» (Leonard, 1979, 219), creo que no sería descabellado identificar a este Trebiña con Pedro. Por su parte, en 1579 el librero Diego de Torres, vecino de Valladolid en la calle de la Librería y su esposa, Juana de Trujillo, fueron llamados por la madre de ésta, Francisca de Trujillo, quien llevaba 16 años en Panamá con su esposo e hijos, en respuesta a las dificultades que pasaban en España: «Escrevisme sois casada con un librero hombre de bien, y que estáis pobres y pasáis trabajos...». A Diego de Torres también le escribe Juan Jiménez del Río, un librero antiguo vecino suyo, instalado ya en Panamá, quien le detalla los pasos a seguir: deberá ir a Sevilla (donde recibiría 200 pesos enviados por su familia política de América) y allí pedir licencia para Tierra Firme y Perú «sin que os desasosegeys de vuestra casa [sic por causa], sino por pasos contados, porque si no binieredes esta flota bendreys la otra». Incluso le envía unas cartas para «el cura Alagalde [sic]», «porque ayude a sacar esas lizençias». Finalmente se le concedió permiso para pasar a Indias con su esposa, su hijo y una mujer de servicio, a cambio de una fianza de 100.000 reales y el compromiso de que residiría en Panamá durante ocho años. Entre sus testigos presentó a los libreros de Valladolid Baltasar Cuello y Pedro Cañete de Ledo. AGI, Indiferente, 2091, N. 23. En 1583 Juan Jiménez del Río estaba en Lima, donde encargó una compra de libros en España a Francisco de la Hoz. Hampe, 1992, 85.

45 AGI, Contratación, 5225A, N.2, R.19 y AGI, Pasajeros, L.5, E. 4008. Encontramos más ejemplos de esposas de libreros que pasaron a Indias, como Catalina Núñez, natural de Aracena, quien en 1593 emigró a Nueva España a «hazer vida» con su marido, el librero Lope Hernández, llevando consigo a sus siete hijos. AGI, Pasajeros, L. 7, E. 2425 y AGI, Contratación, 5538, L.3, 147v. En 1595 era María de Medina, viuda del librero sevillano Alonso de Mata, quien solicitaba licencia para pasar a Cartagena de Indias, donde vivía su padre, junto a sus dos hijos, a causa de su necesidad y pobreza. AGI, Indiferente, 2102, N. 185. En 1566 Isabel Luján, hermana del impresor Pedro de Luján, marchaba a Nueva España con sus cinco hijos. AGI, Pasajeros, L.4, E. 5051. 
con una hija de su primer matrimonio y con su hermano), estuvo casada en primeras nupcias con Melchor Trechel, librero de Toledo (hijo a su vez de Gaspar Trechel y Magdalena de Portonariis, vecinos de Toledo), mientras que ella misma era hija de un librero toledano originario de la provincia de Segovia. ${ }^{46}$ Investigadores como José Toribio Medina han pensado que la esposa de Antonio Ricardo debía ser natural de México y que allí habría contraído matrimonio con el impresor ${ }^{47}$ Este documento confirma que no fue así, pero sobre todo nos permite comprender mejor los lazos familiares que unían a Antonio Ricardo con otros libreros e impresores españoles y europeos.

\section{Otros agentes en la circulación de libros en América}

Por otro lado, no todos los que marchaban al Nuevo Mundo con la intención de comerciar con libros eran necesariamente libreros: Alejo de Herrera envió también como agente a Tierra Firme a Juan Farfán de Illescas, mercader sevillano que preparaba su viaje en 1558, con una caja de libros en latín y castellano encuadernados, que se valoró en 17.000 maravedíes ${ }^{48}$ La presencia de auténticos libreros especializados debió ser escasa en América durante todo el siglo XVI, especialmente para suministrar a los territorios más alejados de las capitales, lo que motivó que los libreros siguieran recurriendo a personas en principio ajenas a su profesión para colocar las mercancías. Además, la lejanía de las nuevas tierras y los mismos peligros que llevaba aparejados la Carrera de Indias, marcaban la necesidad de utilizar varios intermediarios para conseguir que un negocio concreto llegase a buen puerto. Aparte de libreros, entre los destinatarios de los envíos de libros desde Sevilla y los distintos intermediarios que se utilizan para hacer efectivos los pagos hay mercaderes, escribanos, un boticario ${ }^{49}$ funcionarios y gentes sin profesión concreta, así como varios

46 Magdalena, su primera suegra, era hija de Domingo de Portonariis. Puede encontrarse el árbol genealógico de los Portonariis en Ruiz Fidalgo, 1994, I, 66. Por otro lado, su segundo esposo, Antonio Ricardo, natural de Turín, emigró primero a México donde ejerció como librero y después como impresor antes de pasar a Perú.

47 Medina, 1958, 40.

48 AHPS, 3398. s.f.

49 En 1570 Francisco de Aguilar apoderó a Rodrigo Méndez, boticario de Cartagena de Indias, para que cobrase todas sus deudas en Tierra Firme e incluso para que pudiese vender mercancías en su nombre, AHPSe, 3447, 535-536. 
religiosos, quienes constituían al fin y al cabo uno de los colectivos más implicados en la difusión de libros en el Nuevo Mundo.

Los libros eran necesarios para la evangelización de los indígenas, pero también para el normal funcionamiento de conventos e iglesias; además, no pocos religiosos debieron viajar a América con varios volúmenes o incluso bibliotecas bien surtidas, junto a toda la parafernalia que acompañaba a éstas, ya fuera para uso personal, para suministrar a sus órdenes, o con la intención de hacer negocios. No es de extrañar que los libreros recurrieran a este colectivo, familiarizado con el libro y garante de la ortodoxia, para enviar o controlar sus mercancías en América. Tal parece ser el caso de fray Juan Méndez, vicario general del reino de Nueva Granada, quien en 1569 recibió de Francisco de Aguilar dos cajas de libros valoradas en 1.606 reales. La descripción de la carga (libros de latín y romance, encuadernados, de diferentes tamaños, orígenes y materias), me lleva a sospechar que no se trataba de una compra particular para surtir alguna biblioteca eclesiástica, sino que se pretendía hacer negocio con al menos parte de esos volúmenes, que además iban a riesgo y ventura del librero, no del religioso, al igual que ocurriera en 1574, cuando el agustino fray Diego Gutiérrez, general de su orden en el virreinato del Perú, se comprometió a pagar a Aguilar 2.371 reales por tres cajas de libros, también encuadernados y de diferentes materias..$^{50} \mathrm{El}$ mercader de libros Diego Núñez también utilizó a dos dominicos sevillanos que se encontraban de partida hacia Perú en 1590 para cobrar en Lima sus deudas con otro religioso. ${ }^{51}$

Estos eclesiásticos parecen agentes más bien ocasionales de los libreros, sin embargo, a lo largo de los años, se repiten algunos nombres relacionados con distintos libreros, ya fuese recibiendo libros o actuando como intermediarios para cobrar sus deudas o representar sus intereses en América. Aparte del mencionado Juan de Treviño, encontramos a Diego de Agúndez (que trabajó con Francisco Díaz, pero también le enviaron mercancías Miguel Jerónimo y Juan Gutiérrez, todo entre 1563 y 1570); Diego de San Román (apoderado de Pescioni, también envía dinero a Pedro de Portonariis, con cuyo hermano Andrea tenía hecha una compañía); Diego de San Martín (apoderado de Francisco de Aguilar, éste también le envió en 1571 cinco cajas de libros; asimismo recibió tres cajas de libros de Juan

50 AHPSe, 3439, 572-574 y AHPSe, 3466, 864-866.

51 AHPSe, 11613, 71-72. 
Bautista de Alfaro, a quien le envió como resultado 100 pesos, y una caja de Alonso de Fuenmayor, quien le envió libros que había comprado fundamentalmente a Andrea Pescioni); Diego Sansorel (hijo del sevillano Pedro Sansorel y cuñado del impresor Pedro de Ocharte, fue factor de Juan Gutiérrez desde 1566 y había muerto en 1575); o Diego Navarro Maldonado (salmantino, recibe libros de Diego Mexía, es apoderado por Andrea Pescioni y agente en México de Benito Boyer). ${ }^{52}$ Todos ellos ocuparon la primera línea de contacto de los sevillanos y de los libreros de otras ciudades castellanas en Nueva España.

\section{Redes familiares}

Las redes establecidas por los libreros, como ocurría con otro tipo de mercaderes, tenían un fuerte componente familiar, de manera que los parientes servían para anudar distintas localidades, países y continentes. Varios de los factores que encontramos trabajando en Indias están unidos a los libreros peninsulares por lazos de sangre. ${ }^{53}$ Paradigmático es el ejemplo de Pedro de Sansorel y Alonso Montero. Varios hijos de Pedro marcharon a América, entre ellos María ${ }^{54}$ (quien contraería matrimonio con Pedro Ocharte, tercer impresor mexicano $)^{55}$ y Diego de Sansorel, quien sin ser oficialmente librero se implicó en el negocio familiar e incluso sirvió de

52 García Oro y Portela Silva, 1999, 97.

53 En América, los lazos familiares, pero también de amistad o de paisanaje (debido a la falta de parientes en tierras tan lejanas) son fundamentales a la hora de organizar la sociedad que allí se está gestando, dando lugar a una intrincada red de relaciones no siempre fácil de desenmarañar (Testón Núñez y Sánchez Rubio, 2005).

Consultando los catálogos de pasajeros del AGI podemos encontrar a varios familiares de libreros o impresores que marcharon a América y que, en muchas ocasiones y aunque no se diga en el documento, sabemos o sospechamos que se dedicaron al comercio de libros: Luis de Lavezaris, hijo de Sebastián de Lavezaris y Catalina Chaves pasó a Nueva España en 1536 (AGI, Pasajeros, L.2, E.2781); Tomás Cromberger, hijo de Juan Cromberger y doña Brígida Maldonado, se dirigió a Tierra Firme en 1559 (AGI, Pasajeros, L.3, E.4174) y en 1572 Vicente de Portonariis le envió cuatro cajas de libros a Perú que aún no había cobrado en 1577 (Bécares, 2006, 224); en 1560 encontramos a Cristóbal Ruiz, soltero, marchando como mercader a Nueva España, era hijo del librero Pedro Jiménez y su esposa Victoria Ruiz (AGI, Pasajeros, L.4, E.219); en 1563 pasó a Tierra Firme García de Monardes, hijo del doctor Nicolás de Monardes, como factor de su padre (AGI, Pasajeros, L.4, E. 2516); en 1564 Domingo de Portonariis, soltero, hijo de Andrea de Portonariis y Ana Ruiz, se embarcó para Nueva España (AGI, Pasajeros, L. 4, E. 3494) y al año siguiente Pedro de Portonariis le enviaba cierta cantidad de libros para vender en México (AHPSe, 12383. 372).

54 Pasó a Indias en 1566. AGI, Pasajeros, L.4, E. 4739.

55 Stols, 1990. 
agente en México para otros libreros sevillanos, como hemos visto. ${ }^{56}$ Mientras tanto, otra hija de Pedro, Jerónima, se convirtió en esposa del mercader de libros Alonso Montero, quien no sólo se sirvió de sus contactos en Nueva España, sino que envió allí a su propio hijo Gabriel Montero de Espinosa, el cual instalado en México vendió libros a cuenta de su padre en $1583 .{ }^{57}$ Alonso Montero no sólo fue un próspero mercader, sino que también desempeñó el cargo de familiar del Santo Oficio (a pesar de los conocidos problemas que su cuñado Ocharte tuvo con la Inquisición mexicana) y fue distribuidor de los libros del Nuevo Rezado en Andalucía. ${ }^{58}$

\section{Legislación: teoría y práctica}

Otro aspecto interesante que podemos comprender mejor a través de la documentación española es la aplicación efectiva de la legislación que se desarrolló con respecto al libro con destino a América. Al igual que ocurría en España, en Indias la política regia combinó el privilegio (mediante la exención de impuestos) y el control, en el que jugaba un destacado papel el Santo Oficio. El curso que debían recorrer los libros en Sevilla para llegar de forma legal a América ha sido descrito por Pedro Rueda: los volúmenes eran llevados a la aduana de la ciudad para pagar los impuestos y registrarlos en el barco correspondiente. Los libros estaban exentos del almojarifazgo de Indias, aunque la avería, destinada a pertrechar las flotas,

56 Diego marchó a Nueva España en 1561 junto a su hermana Anastasia (AGI, Pasajeros, L. 4, E. 1208), aunque debió volver a España poco después, porque en 1566 lo encontramos de nuevo embarcándose rumbo a México (AGI, Pasajeros, L.4, E.4738). Ese mismo año el aún mercader de libros Juan Gutiérrez le apoderó para cobrar sus deudas en Nueva España «e otrosí para que vna caxa de libros que yo enbío registradas en el registro del rey de la nao nombrada Santa María de Ondis, maestre Esteuan Gómez que va consignada al dicho Diego de Sansorel, la pueda resçibir y vender por los mejores presçios que pudiere, e ansín mismo todas las demás mercaderías e libros que de aquí adelante 1 enbiare y lo proçedido dello con todo [...] demás que por virtud deste poder recibiere y cobrare me lo pueda enbiar y enbíe registrado en el registro del rey de qualesquier nao o naos que quisiere». AHPSe, 3428, s.f. Esta asociación debió prologarse en el tiempo, puesto que en 1575 Diego de Sansorel había fallecido y Juan Gutiérrez, entonces ya impresor, otorgó otro poder al mercader mexicano Diego de Agúndez para liquidar sus deudas y cobrar los libros que le había enviado para vender en Nueva España. AHPSe, 3469, 534-535.

57 Fernández del Castillo, 1982, 397-397, 400 y 555.

58 AHPSe, Leg. 12425, 504 y AHPSe, Leg. 10756, 400-411. Otro hijo suyo, Alonso Montero de Espinosa, fue escribano de los oficios del juzgado en México y en 1584 solicitó ser escribano del rey, para lo que presentó a varios testigos en México y Sevilla. Entre los testigos mexicanos varios dicen saber que su padre era familiar de la Inquisición en la Península. AGI, México, 173, N.1. 
sí debían abonarla. Desde 1550 los títulos debían detallarse en la documentación, aunque parece que esta norma no se cumplió plenamente hasta 1583. Una vez que los libros estaban en la aduana el cargador se dirigía al castillo de la Inquisición, donde presentaba la lista de títulos y se le autorizaba para llevarlos adonde quisiere, previo examen de un calificador. Con ese pase volvía el cargador a la aduana, donde se colocaba a las cajas de libros el sello del Santo Oficio. En la aduana se asienta la salida de los libros hacia el barco donde cruzarán el Atlántico y al cargador se le entrega una copia de la hoja de registro, donde queda certificado que ha abonado los impuestos debidos. Los libros están ya de camino hacia el Nuevo Mundo, donde se instaurarán otros medios de control complementarios. ${ }^{59}$ Varios archivos nos ayudan a conocer cómo era y, sobre todo, cómo se aplicó esa legislación en la práctica, al menos en la primera parte del recorrido que obligatoriamente debían hacer los libros para llegar a América.

Una cédula de 1548 recordaba a los oficiales de Tierra Firme la exención del almojarifazgo de Indias para los libros, que no hacía más que extender la norma aprobada por los Reyes Católicos en las cortes de Toledo de 1480. Esta real cédula se otorgaba precisamente a petición de Cebrián de Caritate, a quien debían devolver el dinero cobrado por una partida de misales y libros eclesiásticos que había enviado a esa parte de las Indias. ${ }^{60}$ Sin embargo, a pesar de las penas impuestas a los infractores, parece que en Sevilla no se dieron por enterados: en 1560 se realiza un testimonio en casa de Hernando de Mazuelos, encargado del cobro del almojarifazgo de Indias. Allí se presentó con un escribano el librero Francisco Díaz en nombre de sus compañeros, y exigieron a Juan de Tovalino, responsable de registrar el cobro de este impuesto, revisar el libro correspondiente a las mercancías enviadas a Tierra Firme y Santo Domingo en 1559. En éste se incluía la partida siguiente: «Pagó [a] Antonio de Maçuelos dos mill y ochoçientos y doze marauedís por vn registro que despachó por Francisco Díaz Andrés de Arçirraga de contado». Tovalino testificó además

quel cobra por el dicho Hernando de Maçuelo los derechos de los libros que se lleuan por mercadería a las Yndias a dos y medio por çiento, porque así vio que los cobraba Hernando Ochoa, arrendador que fue del dicho almoxarifazgo. ${ }^{61}$

59 Rueda Ramírez, 2005, 72.

60 AGI, Panamá, 235, L. 8, 210-211. Encontramos la reproducción de esta cédula en Reyes Gómez, 2000. La norma no deja duda, condenando en 100.000 maravedíes a los infractores.

61 AHPSe, 12365, 269. 
En un segundo documento, otorgado a inicios de febrero, dos mercaderes de libros, Sebastián de Villalón y su hijo Pedro Martínez de Bañares, quien también era impresor, apoderaron al licenciado Pedro de Luján (antiguo impresor él mismo) para pedir ante los Consejos de la Inquisición y de Indias,

çédulas e provisiones reales en nuestro fabor para lo tocante a la mercançía e venta de los dichos libros y al buen despacho dellos, e para que libremente los podamos conprar e vender e añedir y enmendar lo que conforme a lo que está mandado se deve fazer en ellos. E para que a mi, el dicho Pedro Martínez de Bañares, para que se me de liçençia para poder ynprimir los libros que sean católicos e no proyvidos en el catálogo general según la memoria que diere e presentare. E para que a nos anbos los sobre dichos no se nos lleven pedidos ni derechos algunos de alcavala ni almoxarifadgo del aduanilla ni otro alguno, conforme a las provisiones quen razón dello ay. ${ }^{62}$

Los libreros lograron, finalmente, un mayor respeto de sus privilegios: en mayo de 1560 Felipe II otorgaba una real provisión reconociendo que un nutrido grupo de libreros sevillanos habían protestado por el cobro del almojarifazgo de Indias sobre los libros, «que ellos an ynbiado e enbían destos mis reynos a la ciudad de México de la Nueva España y a otras partes de las Yndias [...] para prover las Universidades y Estudios de la dicha ciudad y de los otros pueblos de las dichas Yndias», por lo cual ordenaba al responsable de tal impuesto

que de los libros que los dichos Diego de Aria y Juan de Sevilla ${ }^{63}$ y los otros sus consortes ynbiaren destos Reynos a la dicha Nueva España y a otras qualesquier partes de las Yndias, no le pidáis ni llevéis derechos de almoxarifadgo ni otros algunos derechos. ${ }^{64}$

Pero no eran los libreros e impresores los únicos que enviaban libros a Indias, ni los únicos que tuvieron roces y problemas con los recaudadores del almojarifazgo. Paralelamente a la reclamación planteada por los libreros de Sevilla, se promovió una similar por parte de la Universidad de Mercaderes que consiguió, incluso antes, una real provisión de iguales

62 AHPSe, 14232, 307.

63 Creo que se trata en realidad de Diego de Ciria y Juan de Medina, cuyos nombres figuran además los primeros en la lista de libreros sevillanos que en enero de 1560 apoderó a Pedro de Luján para pedir ante los Consejos del Rey todo aquello que les conviniera. AHPSe, 12365. 235.

64 García Oro y Portela Silva, 1999, 300-301. Por cierto que los libreros habían pedido también que se les devolviesen los derechos ya cobrados, pero esta orden no se incluye finalmente. 
características. Sin embargo, en esta ocasión el almojarife Hernando de Mazuelos protestó: «no ha lugar que se dexen de cobrar los dichos derechos, porque conforme a las leyes y premáticas destos reynos los que lleban o enbían libros destos reynos a las Yndias por trato de grangería no deben gozar de exençión alguna». Todo ello dio lugar a una nueva provisión para certificar el privilegio de los libros. ${ }^{65}$

\section{Conclusiones}

El presente estudio sólo puede ofrecer una pequeña muestra de las posibilidades que nos ofrecen los archivos españoles, y en especial los sevillanos, para estudiar el mercado del libro en el ámbito atlántico, pero aún queda mucho en el tintero. La documentación española viene a confirmar las sospechas que parecen extraerse de la americana: en el siglo XVI, más concretamente en su segunda mitad, las grandes casas europeas se hicieron (a través de Sevilla) con la mejor parte del mercado americano del libro, al igual que se habían hecho antes con el español. ${ }^{66} \mathrm{El}$ estudio sistemático y combinado de la documentación en América y España (pero también en otros lugares clave para la industria del libro, como Italia, los Países Bajos o Francia) nos servirá para conocer el verdadero alcance de este fenónemo, y al mismo tiempo el papel de los libreros como agentes mediadores en el proceso de occidentalización del Nuevo Mundo; pero también nos permitirá preguntarnos hasta qué punto la promesa de enriquecimiento que el mercado americano suponía afectó (o no) a las decisiones editoriales y a las estrategias de negocio de los impresores y libreros europeos, no sólo españoles.

65 Archivo General de Simancas, Registro General del Sello, 3-1-1560 y 7-1-1560. Estos documentos me fueron proporcionados por Rafael M. Pérez García, a quien debo agradecer su generosidad con mi trabajo.

66 Jiménez, 2007, 21. 
APROXIMACIÓN A LA CREACIÓN DE LAS REDES DE DISTRIBUCIÓN DE LIBROS

\section{Bibliografía}

Álvarez Márquez, Carmen: La impresión y el comercio de libros en la Sevilla del Quinientos, Sevilla, Universidad de Sevilla, 2007.

Álvarez Márquez, Carmen: Impresores, libreros y mercaderes de libros en la Sevilla del Quinientos, Zaragoza, Pórtico, 2009, 3 vols.

Bécares Botas, Vicente: Guía documental del mundo del libro salmantino del siglo XVI, Salamanca, Fundación Instituto Castellano Leonés de la Lengua, 2006.

Cañizares Esguerra, Jorge: «Typology in the Atlantic World: Early Modern Readings of Colonization», en Bailyn, Bernard y Denault, Patricia L., Soundings in Atlantic History. Latent Structures and Intellectual Currents, 1500-1830, Cambridge, Mass., Harvard University Press, 2009, 237-264.

Delgado Casado, Juan: Diccionario de impresores españoles (siglos XV-XVII), Madrid, Arco Libros, 1996, 2 vols.

Escudero y Perosso, Francisco: Tipografía Hispalense. Anales bibliográficos de la ciudad de Sevilla, Sevilla, Ayuntamiento de Sevilla, 1999.

Fernández del Castillo, Francisco: Libros y libreros en el siglo XVI, México, FCE, 1982.

García Oro, José y Portela Silva, María José: La monarquía y los libros en el Siglo de Oro, Madrid, Universidad de Alcalá, 1999.

Gestoso Pérez, José: Noticias Inéditas de impresores sevillanos, Sevilla, J. Gómez Hermanos, 1924.

González Sánchez, Carlos Alberto: Los mundos del libro, Sevilla, Universidad de Sevilla, 1999.

González Sánchez, Carlos Alberto y Maillard Álvarez, Natalia: Orbe tipográfico. El mercado del libro en la Sevilla de la segunda mitad del siglo XVI, Gijón, Trea, 2003.

Griffin, Clive: Los Cromberger: la historia de una imprenta del siglo XVI en Sevilla y México, Madrid, Ediciones de Cultura Hispánica, 1991.

Guibovich Pérez, Pedro: Censura, libros e Inquisición en el Perú colonial, 15701754, Sevilla, Escuela de Estudios Hispano-Americanos, CSIC/Universidad de Sevilla, 2003.

Hampe Martínez, Teodoro: «El eco de los ingenios: literatura española del Siglo de Oro en las bibliotecas y librerías del Perú colonial», en Foro Hispánico. Discurso colonial hispanoamericano, Amsterdam, Editions Rodopi B. V., 1992, 77-100.

Jiménez, Nora: «Príncipe indígena y latino. Una compra de libros de Antonio Huitziméngari (1559)», Relaciones. Estudios de Historia y Sociedad, XXIII91, México, 2002, <http://www.redalyc.org/articulo.oa?id=13709106>.

Jiménez, Nora: «Comerciantes de libros en la Nueva España en el siglo XVI. Perfiles y estrategias», en Gutiérrez Lorenzo, María del Pilar (coord.), 
Impresos y libros en la historia económica de México (siglos XVI-XIX), Guadalajara, Universidad de Guadalajara, 2007, 17-40.

Leonard, Irving: Los libros del conquistador, México, F.C.E, 1979.

Lockhart, James: «La formación de la sociedad hispanoamericana», en Pease, Franklin (dir.), Historia general de América Latina, II. El primer contacto y la formación de nuevas sociedades, París, Ediciones UNESCO/Editorial Trotta, 2000, 343-371.

Lohmann Villena, Guillermo: «Libros, libreros y bibliotecas en la época colonial», Fénix. Revista de la Biblioteca Nacional del Perú, 21, Lima, 2000, 1-8.

Maillard Álvarez, Natalia: «Entre Sevilla y América. Una perspectiva del comercio del libro», en Salinero, Gregoire (coord.), Mezclado y sospechoso. Movilidad e identidades, España y América (siglos XVI-XVIII), Madrid, Casa de Velázquez, 2005, 209-228.

Mano González, Marta de la: Mercaderes e impresores de libros en la Salamanca del siglo XVI, Salamanca, Universidad de Salamanca, 1998.

Medina, José Toribio: Historia de la imprenta en los antiguos dominios españoles de América y Oceanía, Tomo I, Santiago de Chile, Fondo Histórico Bibliográfico de José Toribio Medina, 1958.

Reyes Gómez, Fermín de los: El libro en España y América. Legislación y censura (siglos XV-XVIII), Madrid, Arco Libros, 2000.

Rial Costas, Benito (coord.): Print Culture and Peripheries in Early Modern Europe, Leiden, Brill, 2013.

Rojo Vega, Anastasio: «Los grandes libreros españoles del siglo XVI y América», Cuadernos Hispanoamericanos, 500, Madrid, 1992, 115-131.

Rueda Ramírez, Pedro: «Los libreros Mexía en el comercio de libros con América en los últimos años del reinado de Felipe II», en Felipe II (1527-1598). Europa y la Monarquía Católica, Tomo IV, Madrid, Parteluz, 1998, 477-496.

Rueda Ramírez, Pedro: «Mercaderes de libros en la Carrera de Indias a finales del reinado de Felipe II», en $V$ Reunión Científica. Asociación Española de Historia Moderna. Tomo I. Felipe II y su tiempo, Cádiz, Universidad de Cádiz, 1999, 565-572.

Rueda Ramírez, Pedro: «La circulación de libros desde Europa a Quito en los siglos XVI-XVII», Procesos, Revista Ecuatoriana de Historia, 15, Quito, 2000, 3-20.

Rueda Ramírez, Pedro: «En torno a las librerías sevillanas: almacenes de libros para Andalucía y el Nuevo Mundo», en La cultura en Andalucía. Vida, memoria y escritura en torno a 1600, Estepa, Ayuntamiento de Estepa, 2001, 251-269.

Rueda Ramírez, Pedro: «Libros a la mar: el libro en las redes comerciales de la Carrera de Indias», en Castillo Gómez, Antonio (ed.), Libro y lectura en la Península Ibérica y América. Siglos XIII-XVIII, Salamanca, Junta de Castilla y León, 2003, 189-207. 
Rueda Ramírez, Pedro: Negocio e intercambio cultural: El comercio de libros con América en la Carrera de Indias (siglo XVII), Sevilla, Universidad de Sevilla, 2005.

Ruiz Fidalgo, Lorenzo: La imprenta en Salamanca (1501-1600), Madrid, Arco Libros, 1994.

Sánchez Rubio, Rocío y Testón Núñez, Isabel: El hilo que une. Las relaciones epistolares en el viejo y el Nuevo Mundo (Siglos XVI-XVIII), Mérida, Universidad de Extremadura, 1999.

Sánchez Rubio, Rocío y Testón Núñez, Isabel: «"Para hacer la raya enviamos un sobrino". El papel de la familia y el parentesco en las relaciones de la América española (siglo XVI)», en Salinero, Gregoire (coord.), Mezclado y sospechoso. Movilidad e identidades, España y América (siglos XVI-XVII), Madrid, Casa de Velázquez, 2005, 91-119.

Stols, Alexandre A.M.: Pedro Ocharte, el tercer impresor mexicano, México, Biblioteca Nacional, 1990.

Van Rossem, Stijn: «The Verdussens and the International Trade in Catholic Books (Antwerp, Seventeenth Century)», en Maillard Álvarez, Natalia (ed.), Books in the Catholic World during the Early Modern Period, Leiden, Brill, 2014, $1-51$.

Wagner, Klaus: «Libros para el convento de Santo Domingo de Coyoacán», Historiografía y Bibliografía Americanistas, XXIII, Sevilla, 1979, 117-119.

Wagner, Klaus: «Guido de Lavezaris, genovés (1512-1582). De librero a gobernador de Filipinas», en Tra Siviglia e Genova: notario, documento e commercio nell'età colombiana, Milán, Dott. A. Giufrrè Editore, 1994, 378-391. 